\title{
Inhibitory effects of Euphorbia supina on Propionibacterium acnes-induced skin inflammation in vitro and in vivo
}

Hyeon-Ji Lim', Yong-Deok Jeon ${ }^{1 \dagger}$ DD, Sa-Haeng Kang ${ }^{2}$, Min-Kyoung Shin ${ }^{1}$, Ki-Min Lee', Se-Eun Jung ${ }^{1}$, Ji-Yun Cha ${ }^{2}$, Hoon-Yoen Lee ${ }^{2}$, Bo-Ram Kim², Sung-Woo Hwang ${ }^{2}$, Jong-Hyun Lee ${ }^{3}$, Takashi Sugita ${ }^{4}$, Otomi Cho ${ }^{4}$, Hyun Myung ${ }^{5}$, Jong-Sik Jin ${ }^{1 *}$ and Young-Mi Lee ${ }^{2^{*}}$

\begin{abstract}
Background: Euphorbia supina (ES) plant has been used as treatment for inflammatory conditions. The antibacterial effect and the anti-inflammatory mechanism of ES for Propionibacterium (P.) acnes-induced inflammation in THP-1 cells and acne animal model remain unclear. Therefore, the objective of the present study was to determine the antibacterial and anti-inflammatory activities of ES against $P$. acnes, the etiologic agent of skin inflammation.

Method: The antibacterial activities of ES were tested with disc diffusion and broth dilution methods. Cytotoxicity of ES at different doses was evaluated by the MTT assay. THP-1 cells were stimulated by heat-killed $P$. acnes in the presence of ES. The pro-inflammatory cytokines and mRNA levels were measured by ELISA and real-time-PCR. MAPK expression was analyzed by Western blot. The living $P$. acnes was intradermally injected into the ear of BLBC/C mice. Subsequently, chemical composition of ES was analyzed by liquids chromatography-mass spectrometry (LC-MS).

Result: ES had stronger antibacterial activity against $P$. acnes and inhibitory activity on lipase. ES had no significant cytotoxicity on THP-1 cells. ES suppressed the mRNA levels and production of IL-8, TNF-a, IL-1 $\beta$ in vitro. ES inhibited the expression levels of pro-inflammatory cytokines and the MAPK signaling pathway. Ear thickness and inflammatory cells were markedly reduced by ES treatment. Protocatechuic acid, gallic acid, quercetin, and kaempferol were detected by LC-MS analysis in ES.
\end{abstract}

Conclusions: Our results demonstrate antibacterial and anti-inflammatory activities of ES extract against $P$. acnes. It is suggested that ES extract might be used to treatment anti-inflammatory skin disease.

\section{Background}

Acne, one of the most common skin diseases, affects more than $80 \%$ of all adolescents [1]. Acne is an inflammatory disorder of the pilosebaceous unit characterized by excessive sebum production, follicular hyperkeratinization, and colonization of Propionibacterium (P.) acnes [2], a Grampositive anaerobic bacterium. It has been reported that $P$. acnes is a major factor in acne inflammatory reaction by

\footnotetext{
* Correspondence: jongsik.jin@jbnu.ac.kr; ymlee@wku.ac.kr

${ }^{\dagger}$ Hyeon-Ji Lim and Yong-Deok Jeon contributed equally to this work.

'Department of Oriental Medicine Resources, Chonbuk National University,

79 Gobongro, Iksan, Jeollabuk-do 54596, South Korea

${ }^{2}$ Department of Oriental Pharmacy, College of Pharmacy, Wonkwang-Oriental Medicine Research Institute, Wonkwang University, Iksan, Jeollabuk-do 54538, South Korea

Full list of author information is available at the end of the article
}

activating toll-like receptors TLR2 and TLR4 [3]. During acne inflammatory reaction, $P$. acnes induces the production of pro-inflammatory cytokines such as interleukin (IL)-1 $\beta$, IL-6, IL-8, and tumor necrosis factor (TNF)- $\alpha$ in monocytes and keratinocytes $[4,5]$. IL-8, a CXC chemokine, is a strong proinflammatory chemotactic factor for lymphocytes, basophils, and neutrophils. It is increased in keratinocytes by $P$. acnes stimulation [6]. Therefore, suppression of $P$. acnes-induced inflammatory cytokine is one of the major targets for treating acne inflammation.

Euphorbia supina (ES) plant has been used for traditional formulations of herbal medications. It has various pharmacological effects, including anti-oxidant, anti-arthritic, detoxification, diuretic, and hemostatic effects in various cell types [7]. ES contains a number of biologically organic

(c) The Author(s). 2018 Open Access This article is distributed under the terms of the Creative Commons Attribution 4.0 International License (http://creativecommons.org/licenses/by/4.0/), which permits unrestricted use, distribution, and reproduction in any medium, provided you give appropriate credit to the original author(s) and the source, provide a link to the Creative Commons license, and indicate if changes were made. The Creative Commons Public Domain Dedication waiver (http://creativecommons.org/publicdomain/zero/1.0/) applies to the data made available in this article, unless otherwise stated. 
substances including tannins, terpenoids, and polyphenols [8]. Recent studies have shown that ES possesses antibacterial activity against Staphylococcus aureus [9]. It can also inhibit cancer cell proliferation of U937 human leukemic cells [10]. However, the antibacterial effect and anti-inflammatory mechanism of ES in P. acnes-induced inflammation in vitro and in vivo remain unclear. Therefore, the objective of this study was to determine the antibacterial and anti-inflammatory effects of ES in an in vitro model using heat-killed $P$. acnes and living $P$. acnes-induced acne skin disease model.

\section{Methods}

\section{ES preparation}

The dried ES was purchased from Wonkwang PHARMACEUTICAL CORPORATION (Iksan, Korea). ES was washed twice with distilled water followed by drying, then extracted with $70 \%$ ethanol at room temperature for 3 days. The extract was concentrated with a vacuum evaporator and stored at $4{ }^{\circ} \mathrm{C}$ before experiments. The yield of ES extract was $6.14 \%$. A voucher specimen (JUHES-1660) has been deposited at Department of Oriental Medicine Resources, Chonbuk National University (Iksan, Korea).

\section{Preparation of P.acnes}

$P$. acnes (KCTC 3315, Daejeon, Korea) was obtained from the Korean Collection for Type Culture (KCTC, Daejeon, Korea) and grown under anaerobic condition in $10 \mathrm{ml}$ of GAM (Nissui Pharmaceutical, Japan) liquid medium at $37{ }^{\circ} \mathrm{C}$ for OD600 $=1.0$ (logarithmic growth phase). A total cell count of $10 \mathrm{ml}$ of P.acnes suspension was approximately $1.34 \times 10^{9}$ colony forming unit (CFU). P. acnes were harvested by centrifugation at $4000 \mathrm{rpm}$ for $15 \mathrm{~min}$ at $4{ }^{\circ} \mathrm{C}$ to remove supernatant. Bacterial pellets were washed three times with $10 \mathrm{ml}$ of PBS and finally suspended in $1 \mathrm{ml}$ of PBS. The $P$. acnes suspension was incubated at $80{ }^{\circ} \mathrm{C}$ for $30 \mathrm{~min}$ for heat-killing reaction. To use cell stimulation heat-killed $P$. acnes suspension was stored at $4{ }^{\circ} \mathrm{C}$ until use. To use in vivo experiment living $P$. acnes suspension was stored at $-80{ }^{\circ} \mathrm{C}$ until use.

\section{Antibacterial assay}

ES was dissolved in dimethyl sulfoxide (DMSO) at different concentrations $(100,200 \mathrm{mg} / \mathrm{ml})$. Each concentration of ES was then impregnated onto a paper disc ( $8 \mathrm{~mm}$ in diameter) and placed on the top of GAM agar plate containing $100 \mu \mathrm{l}$ of bacterial solution containing $P$. acnes. These plates were incubated at $37{ }^{\circ} \mathrm{C}$ for $48 \mathrm{~h}$ under anaerobic condition. Tetracycline was employed as a positive control. Minimum inhibitory concentration (MIC) test was performed in sterile 96-well plates using broth dilution method. Briefly, bacteria were cultured to stationary phase for $48 \mathrm{~h}$ at $37{ }^{\circ} \mathrm{C}$. The turbidity and cell numbers were measured 0.418 at $620 \mathrm{~nm}$ and $1.64 \times$ $10^{7} \mathrm{CFU}$, respectively. The cultivated bacteria was added into microplate at $0.5 \%$ of total volume $(200 \mu \mathrm{l})$. ES extract was adjusted to concentrations through serial dilution in culture medium into 0 to $9 \mathrm{mg} / \mathrm{ml}$. After incubating at $37^{\circ} \mathrm{C}$ in an anaerobic jar for $48 \mathrm{~h}$, the turbidity was obtained on a microplate ELISA reader as an indicator of bacterial growth.

To test minimum bactericidal concentration $(\mathrm{MBC})$, $1 \mu \mathrm{l}$ of various concentrations of the ES extract mixed with diluted solution of $P$. acnes for $48 \mathrm{~h}, 37{ }^{\circ} \mathrm{C}$. And then $\mathrm{MBC}$ was performed by sub culturing the MIC dilutions on the sterile GAM agar broth. The lowest concentration of the extract in which bacteria failed to grow (99\% no growth) was reported as MBC.

\section{Lipase activity}

P.acnes was grown in brain heart infusion (BHI) broth, and $100 \mu \mathrm{l}$ amounts of cell suspensions $\left(5.0 \times 10^{8}\right.$ cells $\left./ \mathrm{mL}\right)$ in BHI broth with final concentrations of $0.01,0.1,1,10$, $100 \mu \mathrm{g} / \mathrm{mL}$ ES were added to wells of 96well plates. The plates were anaerobically incubated at $37^{\circ} \mathrm{C}$ for $24 \mathrm{~h}$. Fifty microliter amounts of supernatants were centrifuged and the supernatants mixed with $50 \mu \mathrm{l}$ of $10 \mathrm{mM}$ 4-methyl umbelliferyl oleate (4-MUO) (Sigma Aldrich, St. Louis, USA) dissolved in $13 \mathrm{mM}$ Tris-HCL, $0.15 \mathrm{M} \mathrm{NaCl}$, and $1.3 \mathrm{mM} \mathrm{CaCl}_{2}(\mathrm{pH} 8.0)$. The mixtures were incubated for $30 \mathrm{~min}$ at $25{ }^{\circ} \mathrm{C}$ under light illumination. Enzymatic reactions were terminated by adding $100 \mu \mathrm{l}$ of $0.1 \mathrm{M}$ sodium citrate ( $\mathrm{pH} 4.2)$. The levels of 4-methylumbelliferone released by the lipase were measured using a fluorometric microplate reader (Fluoroskan Ascent ${ }^{\mathrm{m} w}$; Thermo Fisher Scientific, MA, USA); the excitation wavelength was $355 \mathrm{~nm}$ and the emission wavelength was $460 \mathrm{~nm}$.

\section{Cell viability assay}

Human monocyte THP-1 cells were maintained in RPMI 1640 (Gibco, Carlsbad, CA, USA) supplemented with $10 \%$ fetal bovine serum (FBS, WELGENE, South Korea) and $1 \%$ penicillin (Gibco, USA) at $37{ }^{\circ} \mathrm{C}$ in an atmosphere with $5 \% \mathrm{CO}_{2}$.

MTT assay was performed to measure cell viability. Briefly, THP- 1 cells $\left(3.0 \times 10^{4}\right.$ cells/well $)$ was incubated with various concentration of ES $(0.1-10 \mu \mathrm{g} / \mathrm{ml})$ for $24 \mathrm{~h}$. MTT solution $(500 \mu \mathrm{g} / \mathrm{ml})$ was then added to each well and incubated at $37{ }^{\circ} \mathrm{C}$ for $8 \mathrm{~h}$. Formazan crystal produced by living cell was dissolved in DMSO. The absorbance of each well was measured at wavelength of $540 \mathrm{~nm}$ on a microplate ELISA reader.

\section{Enzyme-linked immunosorbent assay (ELISA)}

THP-1 cells $\left(3.0 \times 10^{5}\right.$ cells/well $)$ were pre-treated with indicated concentrations of ES $(0.1-10 \mu \mathrm{g} / \mathrm{ml})$ for $1 \mathrm{~h}$ followed by stimulation with heat-killed P. acnes for $18 \mathrm{~h}$. 
The levels of IL-1 $\beta$, IL-8, and TNF- $\alpha$ in culture media were measured with an ELISA kit (BD Pharmingen, San Diego, CA, USA). The absorbance of the ELISA plate was measured at wavelength of $405 \mathrm{~nm}$ using an automated microplate ELISA reader.

\section{RNA isolation and real- time RT PCR}

Total cellular RNA was isolated from human monocyte THP-1 cells using easy-BLUE reagent Kit (iNtRON Biotechnology, Seoul, South Korea). Total RNA was used as template for first-strand cDNA synthesis using a Power cDNA Synthesis Kit (iNtRON Biotechnology, Seoul, South Korea) according to the manufacturer's instructions. The transcription levels of genes were determined with a StepOnePlus Real-time PCR System (Applied Biosystems, Foster City, CA, USA). The relative gene expression was calculated using the comparative CT method with StepOne Software v2.1 (Applied Biosystems, Foster City, CA, USA). The expression of $\beta$-actin mRNA was used as an endogenous control. We used TNF-Forward primer 5'-TTACGCCTT TGAAGTTAGCAG-3' and TNF-Reverse primer 5'-CGTC CAAATACATCGCAAC-3' for TNF- $\alpha, 5^{\prime}$ - TCTTTGAAG AAGAGCCCGTCCTC- 3' /5'-GGATCCACACTCTCCA GCTGCA- 3' for IL-1 $\beta$, and 5' - GAATACTCTATTGC CGATGGT-3'/5'-CGATGGGTTTGCGTTTG-3' primers for $\beta$-Actin as an internal control.

\section{Western blot analysis}

Stimulated cells were rinsed with ice-cold PBS and lysed using lysis buffer (iNtRon Biotech, Seoul, South Korea) for $1 \mathrm{~h}$. Total cell lysates were centrifuged at $12,000 \times \mathrm{g}$ at $4{ }^{\circ} \mathrm{C}$ for $10 \mathrm{~min}$ to obtain supernatants. After bicinchoninic acid (BCA, Sigma) protein quantification assay, the supernatant was mixed with $2 \times$ sample buffer, boiled at $95{ }^{\circ} \mathrm{C}$ for $5 \mathrm{~min}$, separated by $10 \%$ SDS-polyacrylamide gel electrophoresis, and transferred to nitrocellulose membrane (Roche Diagnostics, IL, US). These membranes were blocked with 5\% skim milk in PBS-Tween-20 (PBST) for $1 \mathrm{~h}$ at room temperature followed by overnight incubation with antiphospho-JNK, anti-p38, and anti-ERK antibodies at $4{ }^{\circ} \mathrm{C}$. After washing three times with PBST, these membranes were incubated with secondary antibodies for $1 \mathrm{~h}$ at room temperature followed by three times of washes with PBST. The protein-antibody complexes were visualized with ECL Western blotting Luminol Reagent (Santa Cruz Biotech, CA, USA). Images were recorded with an LAS-4000 image reader (Fujifilm Life Sciences, Tokyo, Japan).

\section{Experimental animal model}

All experimental protocols (CBNU2016-085) were approved by the Committee on the Care of Laboratory Animal Resources, Chonbuk National University and were conducted in accordance with the Guide for the Care and Use of Laboratory Animals. Male BALB/c mice
(6 weeks old) were obtained from SAMTAKO (Osan, South Korea). They were individually housed in polycarbonate cages and maintained under constant temperature $\left(25-27^{\circ} \mathrm{C}\right)$ with a $12 \mathrm{~h}$ light-dark cycle. They were provided free access to standard diet and tap water. These animals were allowed to acclimate to these conditions for at least 7 days before the experiment.

These mice were randomly divided into 4 different groups (4 mice/group) as follows: B: non-treatment, PA: Live $P$. acnes $\left(1.34 \times 10^{9} \mathrm{CFU} / 20 \mu \mathrm{lBS}\right)$ was intradermally injected into the left ear. The right ear was received an equal amount of PBS. PA/ES $1 \mathrm{mg}$ and PA/ES $10 \mathrm{mg}$ with live $P$. acnes were intradermal injected into both the left and right ears. At $24 \mathrm{~h}$ after the injection, ES (1 or $10 \mathrm{mg} / \mathrm{ml}$ in PBS) was applied to the surface of the right ear skin of each group. At the end of each treatment period, these animals were sacrificed by cervical dislocation and their ears were measured using a micro-caliper (Mitutoyo, Kanagawa, Japan).

\section{Histological analysis}

Ear section sample was fixed with 10\% formaldehyde, embedded in paraffin wax, routinely processed and sectioned into 4- $\mu \mathrm{m}$-thick slices. These ear sections were stained with hematoxylin and eosin (H\&E) followed by examination with a light microscope to determine the presence of edema and inflammatory cell accumulation.

\section{HPLC-MS}

The extract of ES was dissolved in $\mathrm{MeOH}$ into $0.1 \mathrm{mg} / \mathrm{ml}$. Gallic acid (Sigma aldrich chemie GmbH, Germany), protocatechuic acid (Hwi analytik $\mathrm{GmbH}$, Germany), quercetin

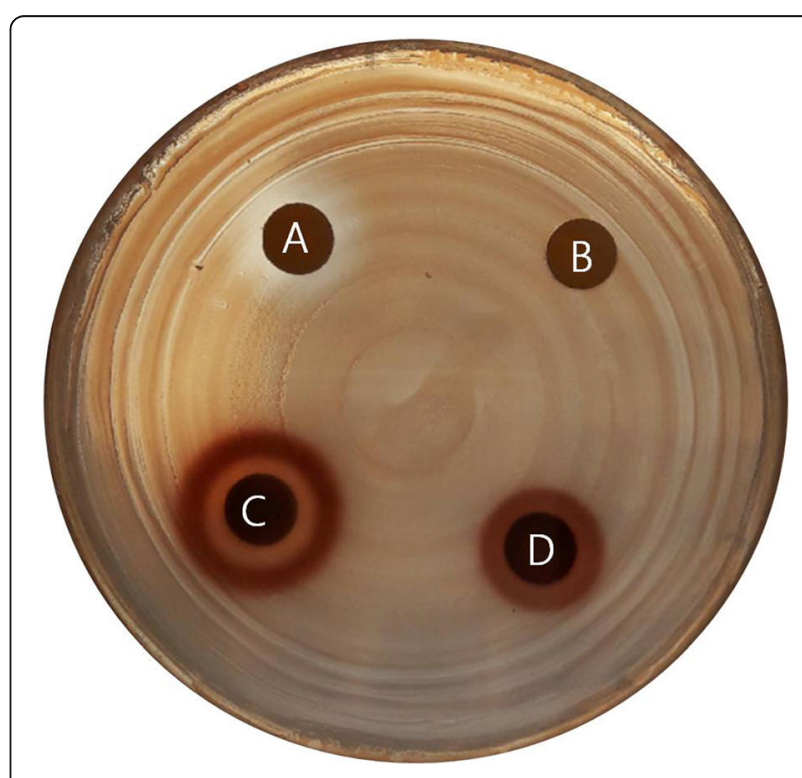

Fig. 1 Antibacterial activity of ES against $P$. acnes (a; tetracycline 50 $\mu \mathrm{g} / \mathrm{ml}$, b; DMSO, c; ES $200 \mathrm{mg} / \mathrm{ml}$, d; ES $100 \mathrm{mg} / \mathrm{ml}$ ) 
Table 1 The inhibitory effect of ES on lipase activity. P.acnes $(5.0 \times 108$ cells/ $\mathrm{ml}$ ) and $0.01-.100 \mu \mathrm{g} / \mathrm{ml}$ of ES were added to 96 well plates. $24 \mathrm{~h}$ later, $50 \mu \mathrm{l}$ of supernatants were mixed with $50 \mu \mathrm{l}$ of 4-MUO. 30 min later, $100 \mu$ l of 0.1 M sodium citrate was added. Then lipase.activity was measured using fluorometric microplate reader. Values represent mean $\pm \mathrm{SD}(n=$.4). Data were analyzed by Tukey post hoc test ( ${ }^{*} P<0.05$ versus $P$.acnes alone)

\begin{tabular}{llll}
\hline & & Inhibition (\%) & SD \\
\hline P.acnes $(5 \times 108 \mathrm{CFU})$ & ES $100 \mu \mathrm{g} / \mathrm{ml}$ & 59.88 & $6.52^{*}$ \\
P.acnes $(5 \times 108 \mathrm{CFU})$ & ES $10 \mu \mathrm{g} / \mathrm{ml}$ & 2.20 & 5.38 \\
P.acnes $(5 \times 108 \mathrm{CFU})$ & ES $1 \mu \mathrm{g} / \mathrm{ml}$ & 5.00 & 8.38 \\
P.acnes $(5 \times 108 \mathrm{CFU})$ & ES $0.1 \mu \mathrm{g} / \mathrm{ml}$ & 0.53 & 2.34 \\
P.acnes $(5 \times 108 \mathrm{CFU})$ & ES $0.01 \mu \mathrm{g} / \mathrm{ml}$ & 0.75 & 3.34 \\
P.acnes $(5 \times 108 \mathrm{CFU})$ & ES $0 \mu \mathrm{g} / \mathrm{ml}$ & & \\
\hline
\end{tabular}

(Tokyo Chemical Industry, Tokyo, Japan) and kaempferol (Santa Cruz Biotechnology Inc., USA) were dissolved in $\mathrm{MeOH}$ for analysis, either. HPLC was performed on an Agilent 1100 system (Agilent Technologies, Waldbronn, Germany) with a photodiode array detector DAD (G1315D) and Agilent 1100 series quard pump (G1311A), and an Agilent 6410 Triple Quadrupole LC/MS mass spectrometer (Agilent Technologies, Waldbronn, Germany) coupled with an ESI (electrospray ionization) interface and an ion trap mass analyzer. The ESI (electrospray ionization) source was operated in negative ionization modes. Analysis of included compounds were performed under the following conditions: column, TSK-gel ODS-80Ts (Tosoh Co., Tokyo, Japan $4.6 \mathrm{~mm}$ X $150 \mathrm{~mm}$ ); mobile phase, 0.1\% formic acid (solvent system A) and $\mathrm{CH}_{3} \mathrm{CN}$ (solvent system B) in a gradient mode (B from 20 to $80 \%$ in $30 \mathrm{~min}$ ); sample injection, $5 \mu \mathrm{l}$; flow rate, $0.5 \mathrm{ml} / \mathrm{min}$; temperature, $30{ }^{\circ} \mathrm{C}$, UV wavelength, $254 \mathrm{~nm}$ and $350 \mathrm{~nm}$. High-purity nitrogen was used as dry gas at a flow rate at $10 \mathrm{~L} / \mathrm{min}$, gas temperature at $300{ }^{\circ} \mathrm{C}$; fragmentor voltage $150 \mathrm{~V}$. Nitrogen was used as nebulizer at 30 psi and capillary voltage, $\pm 4000 \mathrm{~V}$.

\section{Statistical analysis}

All results are presented as mean \pm S.E.M. Results were analyzed using Graph Pad Prism version 5.0 program (Graph Pad Software, Inc., La Jolla, CA, USA). One-way

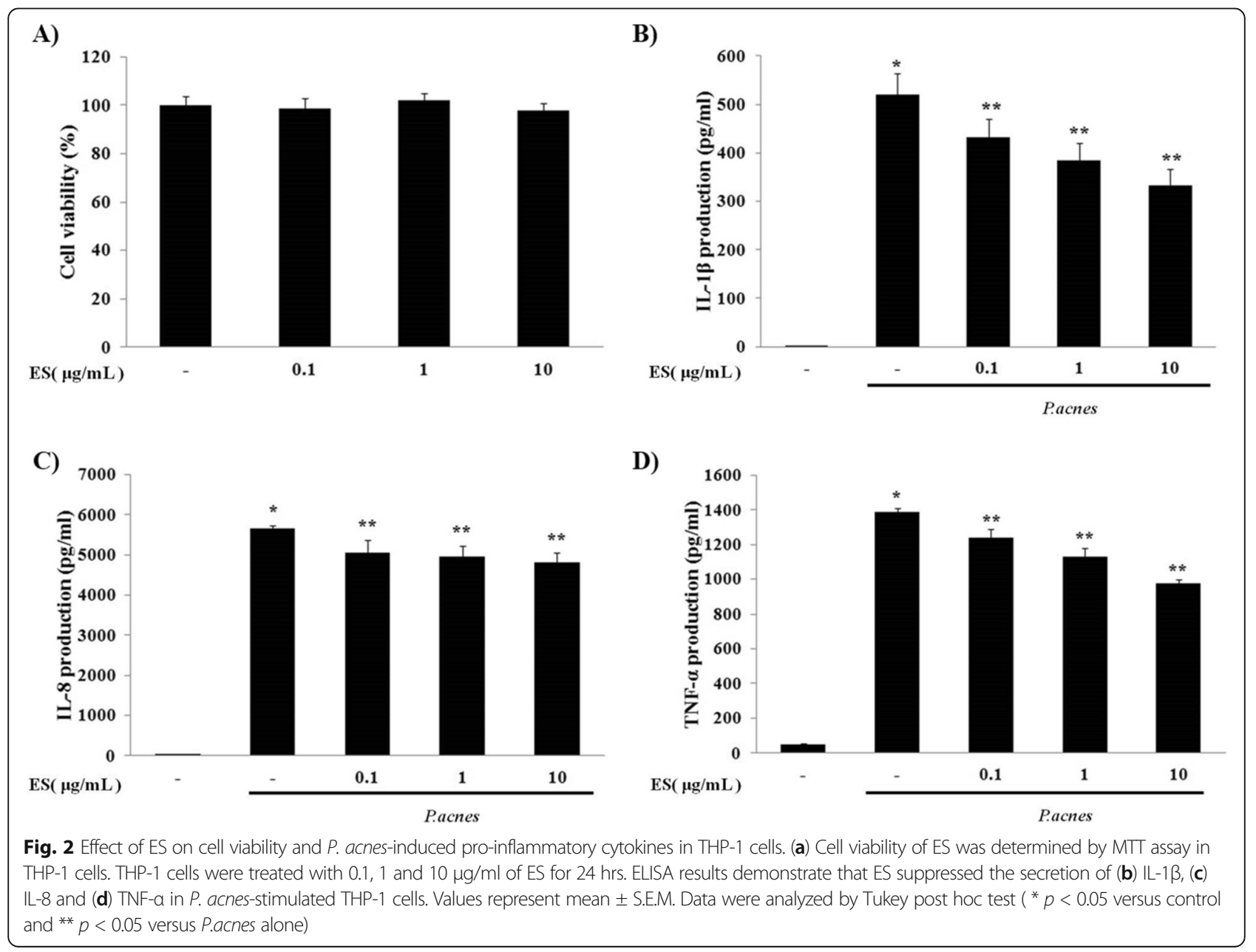




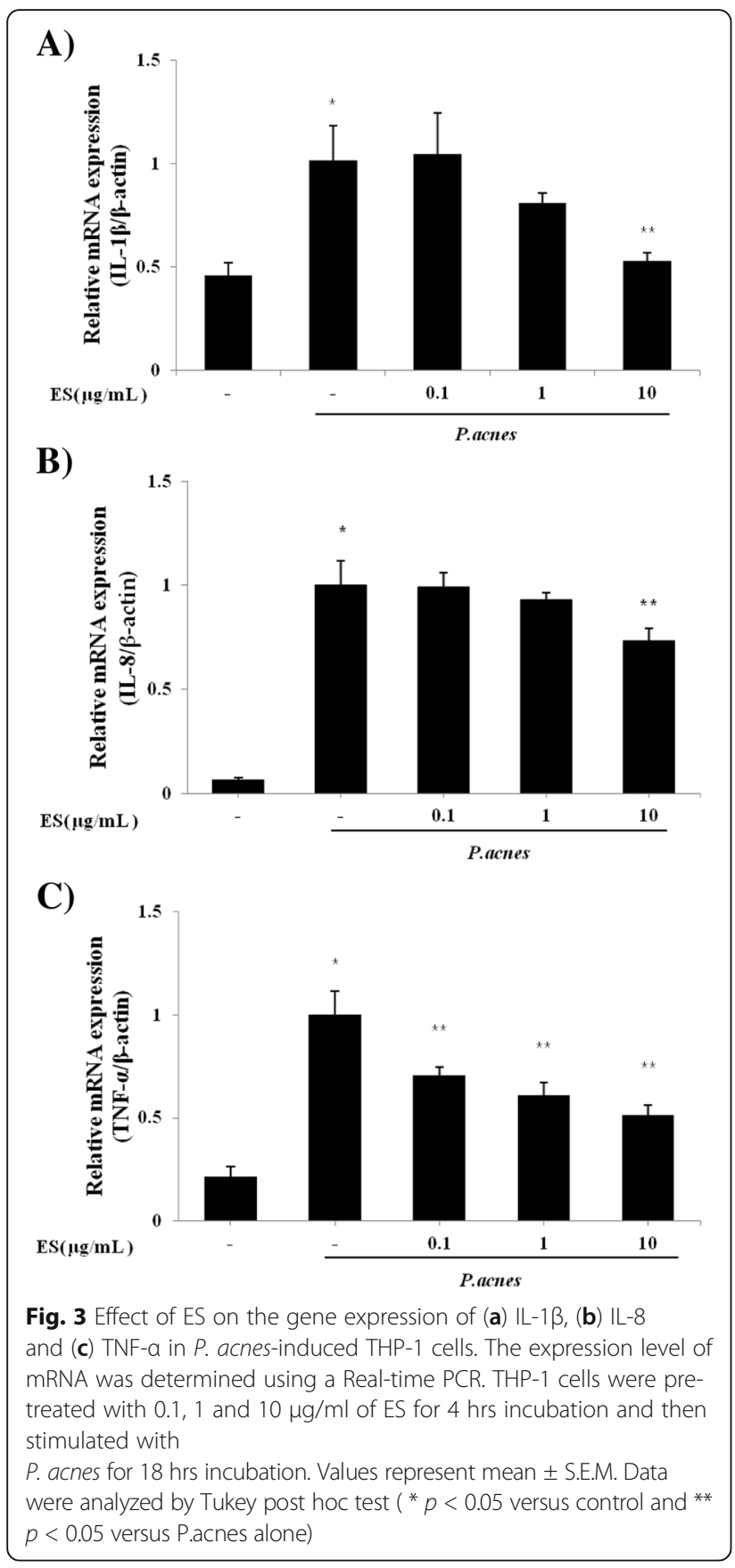

analysis of variance with Tukey hoc post test was used to determine the differences. Statistical significance was considered when $P$ value was less than 0.05 .

\section{Result}

\section{Anti-bacterial activity of ES against $P$. acnes}

To evaluate the antibacterial activity of ES extract against $P$. acnes growth, bacteria was co-cultured with various concentrations of ES for $48 \mathrm{~h}$. The MIC value of
ES was determined to be $3.0 \mathrm{mg} / \mathrm{ml}$. The $\mathrm{MBC}$ value of ES was found to be $7.0 \mathrm{mg} / \mathrm{ml}$. We further performed disc diffusion assay using DMSO as a negative control and tetracycline as a positive control. ES ethanol extracts at concentrations of $100 \mathrm{mg} / \mathrm{ml}, 200 \mathrm{mg} / \mathrm{ml}$, resulted in clear zones of $9.0 \mathrm{~mm}, 14.0 \mathrm{~mm}$ diameter, respectively (Fig. 1). However the lower concentration of ES $(50 \mathrm{mg} / \mathrm{ml}$, $20 \mathrm{mg} / \mathrm{ml}$, and $10 \mathrm{mg} / \mathrm{ml}$ ) had no antibacterial activity against $P$. acnes (data was not shown). In addition, ES had antibacterial activity against other skin microbes such as Propionibacterium granulosum (P. granulosum), Staphylococcus aureus (S. aureus), and Staphylococcus epidermis (S. epidermis) in concentration of $200 \mathrm{mg} / \mathrm{ml}$ (Additional file 1: Figure S1). In addition, ES has effect of lipase inhibition on P.acnes. The production of lipase on P.acnes was reduced by ES treatment $(59.88 \pm 6.52 \%$ on ES $100 \mu \mathrm{g} / \mathrm{ml}$ treatment) (Table 1.).

Effects of ES on heat-killed $P$. acnes-induced proinflammatory cytokines in THP-1 cells

Cell viability of THP-1 cells was determined by MTT assay. THP-1 cells were treated with various concentrations of ES $(0.1,1$, or $10 \mu \mathrm{g} / \mathrm{ml})$ for $24 \mathrm{~h}$. ES had no significant cytotoxicity on THP-1 cells (Fig. 2a). After treatment with ES, the suppressive effect of ES on heat-killed $P$. acnes-stimulated inflammatory cytokine secretion was determined. ES suppressed the secretion of TNF- $\alpha$, IL-1 $\beta$, and IL- 8 in THP-1 cells treated with heat-killed P. acnes. These results suggest that ES could effectively inhibit pro-inflammatory cytokine secretion in $P$. acnes-stimulated THP-1 cells (Fig. 2b, c, d).

We also determined the mRNA expression levels of cytokines after ES treatment by real time RT PCR. Our results showed that ES suppressed the mRNA expression levels of TNF- $\alpha$, IL-1 $\beta$, and IL- 8 in P. acnes induced THP-1 cells (Fig. 3 ).

\section{Regulatory effects of ES on activated MAPK signaling pathway in heat-killed P.acnes-treated THP-1 cells}

To determine the influence of anti-inflammatory properties of ES on MAPK signaling pathway, the levels of MAPK activation were examined by Western blotting analysis. As shown in Fig. 4, the phosphorylation levels of p38, JNK, and ERK were markedly increased in THP-1 cells treated with heat-killed P.acnes. However, ES treatment decreased P. acnes-induced phosphorylation of MAPKs such as p38, JNK, and ERK.

Effects of ES on P. acnes-induced inflammation in vivo To investigate the anti-inflammatory effects of ES on mice ears, live $P$. acnes were intradermally injected into mice ear. At $24 \mathrm{~h}$ post injection of live $P$. acnes, ES $(1 \mathrm{mg} / \mathrm{ml}$ or $10 \mathrm{mg} / \mathrm{ml})$ was injected into mice ears. At $24 \mathrm{~h}$ post ES injection, mice were sacrificed and ear 


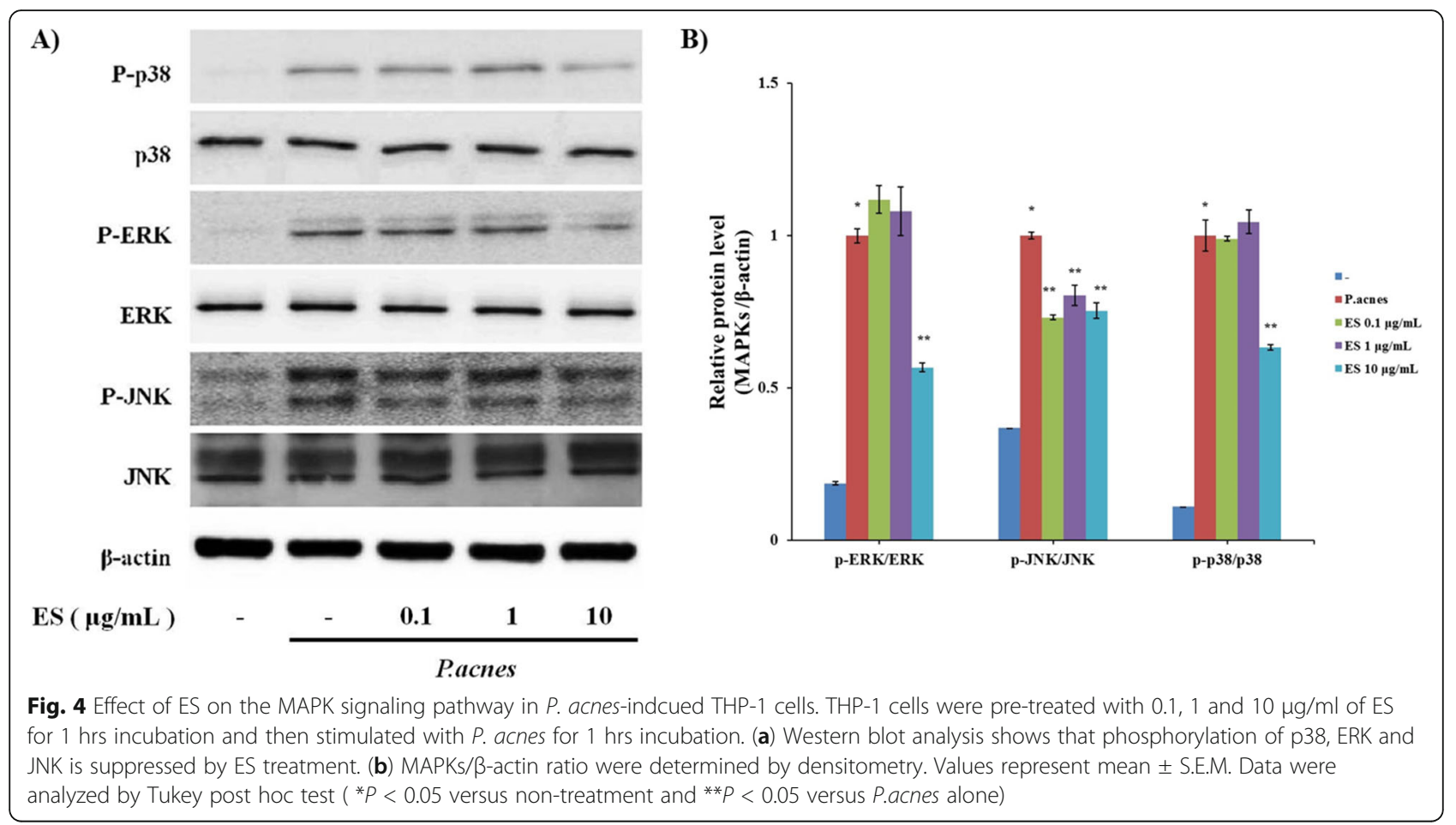

thickness was measured by micro-caliper. The ear thickness of the $P$. acnes-treated group was increased 1.7 fold compared to that of non-treated group. Co-injection of $10 \mathrm{mg} / \mathrm{ml}$ of ES significantly reduced ear thickness (Fig. 5a). Inflammatory cells and thickness of epidermis were observed in H\&E-stained section of $P$. acnes-injected ears. Intradermal injection with ES at 1 or $10 \mathrm{mg} / \mathrm{ml}$ significantly reduced the number of inflammatory cells and thickness of epidermis in a dose dependent manner (Fig. 5b).

\section{Chemical composition of ES}

When analyzed with LC/MS system, the retention times of gallic acid, protocatechuic acid, quercetin and kaempferol were 4.5, 5.6, 17.0 and $19.8 \mathrm{~min}$, respectively (Fig. 6). Quantitative analysis of quercetin and kaempferol gave a concentration of $4.480 \mathrm{mg} / \mathrm{ml}$ and $0.538 \mathrm{mg} / \mathrm{ml}$ in the extract. All of compounds mentioned above, were identified by retention time and molecular ion peak compared with standards.

\section{Discussion}

P. acnes is one of the most abundant bacterium on the skin [2]. Although acnes is not an infectious disorder, the role of $P$. acnes, a Gram-positive bacterium that colonizes on the pilosebaceous unit, has been outlined in

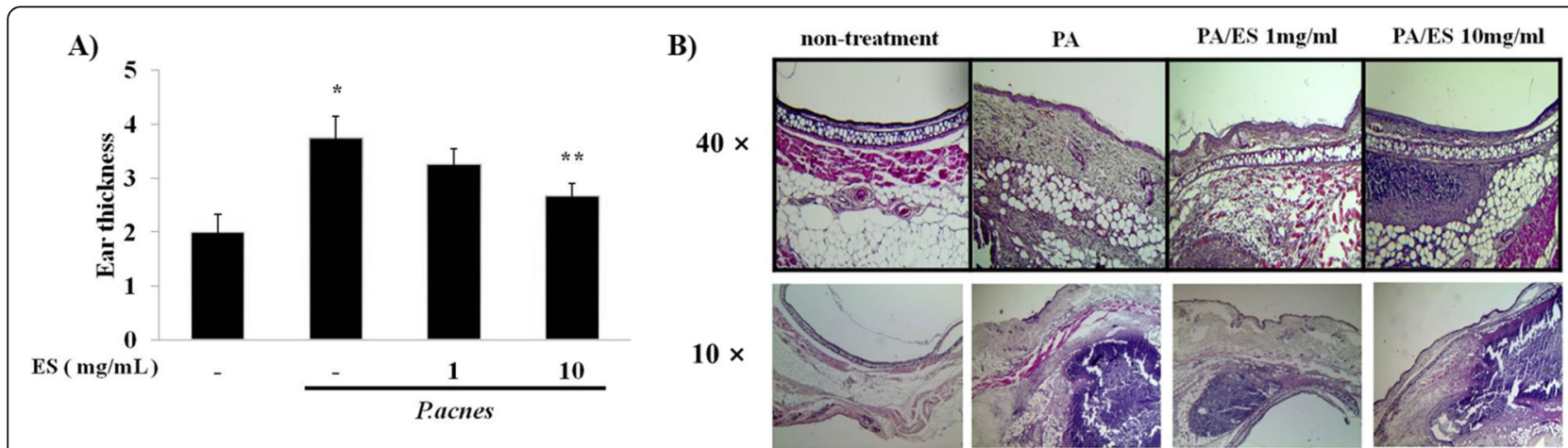

Fig. 5 Effect of ES on ear thickness in living $P$. acnes-injected mice ears. (a) The suppress effects with 1, $10 \mathrm{mg} / \mathrm{ml}$ of ES on $P$. acnes-induced ear edema in mice were evaluated by measuring the ear thickness. (b) Paraffin sections of Ear tissue were stained with H\&E observed by microscope. Values represent mean \pm S.E.M. $(n=5)$. Data were analyzed by Tukey post hoc test ( ${ }^{*} p<0.05$ versus control and ${ }^{* *} p<0.05$ versus P.acnes alone) 


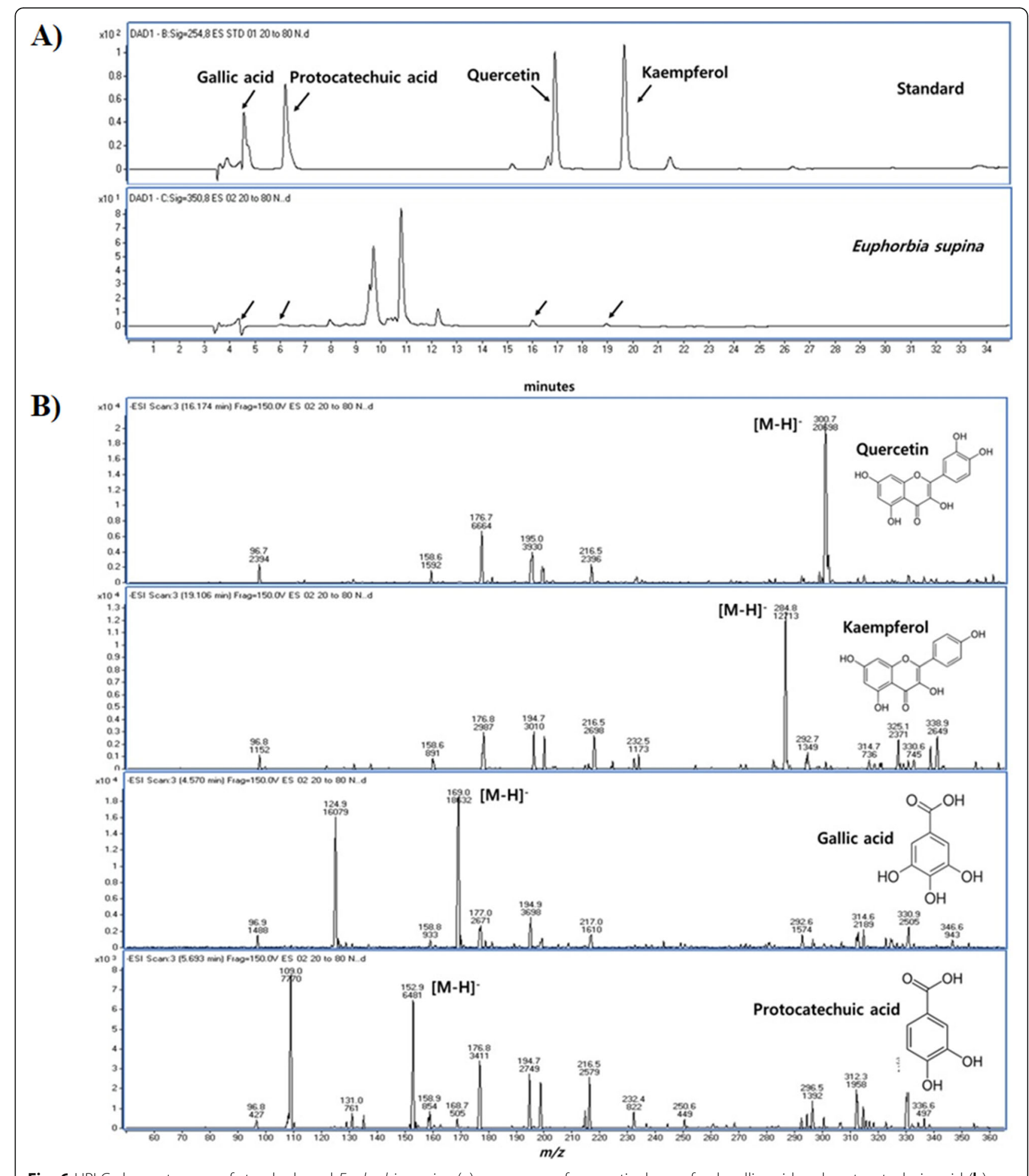

Fig. 6 HPLC chromatogram of standards and Euphorbia supina (a), mass scan of quercetin, kaempferol, gallic acid and protocatechuic acid (b)

previous studies [11]. Injection of P. acnes into sterile keratinous cysts can lead to their rupture with consequent inflammation [12], thus providing evidence of inflammatory properties of $P$. acnes. In addition, heat-killed P.acnes can induce inflammatory response. Heat-killed
P.acnes induced nitric oxide (NO) and IL-8 production in keratinocyte. Also, heat-killed P.acnes influenced activation of p38 MAP kinase [13]. In this study, P.acnes was used to induce inflammatory response including production of pro-inflammatory cytokines in THP-1 cells. 
ES is a species of Euphorbiaceae traditionally used in eastern Asia for medicinal purposes [14]. ES is known to possess biologically active compounds. ES extract has compounds such as gallic acid, protocatechuic acid, nodakenin, quercetin, and kaemferol [8]. Especially, protocatechuic acid, gallic acid, quercetin, and laempferol were found as ingredients of ES (Fig. 6). Protocatechuic acid is known as having suppressive effect on TNBS-induced colitis [15], preventive effect on LPS-induced inflammatory response in fibroblast [16], and anti-oxidative effect [17]. In addition, gallic acid has several effects on allergic reaction [18], type 2 diabetes symptoms [19], oxidative stress, and hypertension [20]. These constituents (protocatetuic acid and gallic acid) might influence the regulatory effect of ES on P.acnes-induced ear inflammation.

Thus, this study investigated the potential of ES as an antibacterial agent for the treatment of acne vulgaris. However, ES has strong antibacterial activity. We observed that ES was nearly equally active against skin flora such as Streptococcus aures (JCM20624), Propionibacterium granulosum (KCTC5747), and Staphylococcus epidermidis (KCTC1917) (Additional file 1: Figure S1). Furthermore, the lipase activity of P.acnes is presented to have role of hydrolysis of sebum triglyceride to free fatty acids. In this process, acnes and skin inflammation is deepen [21]. For this reason, inhibition of lipase is can be a strategy to reduce skin inflammation. ES extract inhibited lipase activity of $P$. acnes (Table 1 ).

Several studies have reported that the anti-inflammatory effects of ES. ES extract has been reported to be able to reduce the levels of inflammatory mediators such as nitric oxide, IL-6, leukotrienes, and $\beta$-hexosaminidase [7]. Recent studies have declared that TNF-a and IL-8 can modulate inflammatory responses in monocytes [22, 23]. Our results showed that $P$. acnes induced secretion of TNF-a, IL-1 $\beta$, and IL- 8 in monocytic THP-1 cells. Moreover, ES treatments effectively inhibited the expression of these cytokines.

The fact that IL-1 $\beta$ is secreted in acne skin condition has proposed valuable effects of IL-1 $\beta$-targeted therapy in patients suffering from anti-inflammatory acne-lesions $[24,26]$. P. acnes is able to induce the secretion of chemokine CXCL8 in monocytes and keratinocyte $[25,26]$. We also observed that the mRNA expression levels of cytokines in P. acnes-induced THP-1 cells were decreased by ES treatment. Our results showed that ES could reduce the expression levels of $P$. acnes-induced TNF-a, IL-8, and IL-1 $\beta$ at transcriptional level.

MAPK and NF-kB pathways have been proposed to be associated with $P$. acnes-induced inflammatory cytokine production [5]. MAPK signaling pathways can adjust cellular reaction to diffusion, differentiation, apoptosis, and inflammation in humans [27]. Previously studies have reported that melitin can suppress MAPK pathway in P. acnes-stimulated $\mathrm{HaCaT}$ keratinocytes [28]. We observed that $P$. acnes activated the phosphorylation of
MAPK in THP-1 cells. Treatment with ES suppressed the phosphorylation levels of p38, JNK, and ERK induced by $P$. acnes.

Based on our in vivo results, we observed the anti-inflammatory effects of ES in $P$. acnes-treated animal model. Several studies have described that injection of live $P$. acnes can lead to the development of inflammatory skin disease in ear-inflammation model [26]. These studies have demonstrated that live $P$. acnes treated group has roughly 2 fold increase in ear thickness compared to PBS treated ear [26]. P.acnes can lead to accumulate immune cells such as neutrophil, monocyte, and eosinophil. Also, P.acnes-injected ear secrets IL-1 $\beta$, MMP-2 and 9, and integrin $\alpha 6$ [29]. Our results also showed that injection of ES $(10 \mathrm{mg} / \mathrm{ml})$ significantly reduced ear thickness and the number of inflammatory cells.

In summary, our results demonstrated the antibacterial and anti-inflammatory effect of ES against $P$. acnes both in vitro and in vivo. ES significantly decreased the expression levels of various inflammatory cytokines in heat-killed $P$. acnes-treated THP-1 monocytic cells. In addition, $P$. acnes-induced inflammatory responses were inhibited by ES treatment through suppressing MAPK phosphorylation. Our results also showed that ES could inhibit $P$. acnes-induced inflammatory response in animal model. Our data suggested that ES extract could be used to treatment anti-inflammatory skin disease.

\section{Conclusions}

ES extract has shown strong antibacterial activity against $P$. acnes. ES extract suppressed pro-inflammatory cytokines and MAPK signaling pathway. ES extract inhibited dermatitis in a mice model of acnes induced by intradermal injection of $P$. acnes. This study provides that ES extract might be used to treatment anti-inflammatory skin disease.

\section{Additional file}

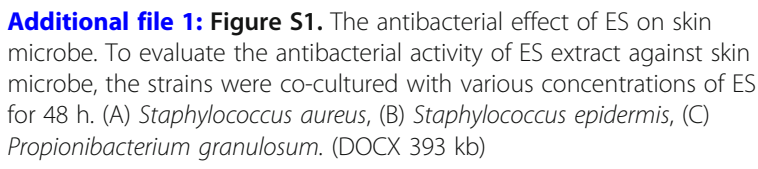

Additional file 1: Figure S1. The antibacterial effect of ES on skin microbe. To evaluate the antibacterial activity of ES extract against skin microbe, the strains were co-cultured with various concentrations of ES for 48 h. (A) Staphylococcus aureus, (B) Staphylococcus epidermis, (C) Propionibacterium granulosum. (DOCX 393 kb)

\section{Funding}

This research was financially supported by the Ministry of Trade, Industry \& Energy (MOTIE), Korea Institute for Advancement of Technology (KIAT) through the Encouragement Program for The Industries of Economic Cooperation Region (R0004536).

\section{Availability of data and materials}

The raw data used and/or analyzed during this study are available from the corresponding authors upon reasonable request.

\section{Authors' contributions}

$H J L$ and YDJ performed the in vivo mouse model experiment and analyzed data. SHK, JYC, HYL, JHL, BRK, and SWH supported the in vitro experiment and collected data. KML, TS and OC provided technical and material support 
about microbial experiments. MKS performed analysis of extract constituent. HM provided detail and botanic information of ES. HJL and YDJ collected the data, undertook the statistical analyses, and wrote the manuscript. YML and JSJ designed and supervised the study, including editing of the manuscript. All authors shared the raw data of this experimental study. Also, all authors contributed to and have approved the final manuscript.

\section{Ethics approval and consent to participate}

All experimental protocols (CBNU 2016-85) were approved by the committee on the Care of Laboratory Animal Resources, Chonbuk National University and were conducted in accordance with Guide for the Care and Use of Laboratory Animals.

\section{Consent for publication}

Not relevant in this study.

\section{Competing interests}

The authors declare that there are no conflicts of interest

\section{Publisher's Note}

Springer Nature remains neutral with regard to jurisdictional claims in published maps and institutional affiliations.

\section{Author details}

'Department of Oriental Medicine Resources, Chonbuk National University, 79 Gobongro, Iksan, Jeollabuk-do 54596, South Korea. ${ }^{2}$ Department of Oriental Pharmacy, College of Pharmacy, Wonkwang-Oriental Medicine Research Institute, Wonkwang University, Iksan, Jeollabuk-do 54538, South Korea. ${ }^{3}$ Department of Pharmacy, College of Pharmacy, Dongduk Woman's University, 23-1 Wolgok-Dong, SungBuk-Gu, Seoul 02748, South Korea. ${ }^{4}$ Department of Microbiology, Meiji Pharmaceutical University, 2-522-1 Noshio, Kiyose, Tokyo 204-8588, Japan. ${ }^{5}$ Department of Ecology Landscape Architecture-Design, College of Environmental and Bioresource Sciences, Chonbuk National University, Iksan, South Korea.

\section{Received: 19 April 2018 Accepted: 5 September 2018}

\section{Published online: 27 September 2018}

\section{References}

1. Grange PA, et al. Production of superoxide anions by keratinocytes initiates P. acnes-induced inflammation of the skin. PLoS Pathog. 2009;5(7):e1000527.

2. Williams HC, Dellavalle RP, Garner S, Sarah. Acne vulgaris. Lancet. 2012; 379(9813):361-72

3. Jugeau $\mathrm{S}$, et al. Induction of toll-like receptors by Propionibacterium acnes. Br J Dermatol. 2005;153(6):1105-13.

4. Vowels BR, YANG S, LEYDEN, James J. Induction of proinflammatory cytokines by a soluble factor of Propionibacterium acnes: implications for chronic inflammatory acne. Infect Immun. 1995;63(8):3158-65.

5. Huang W-C, et al. Anti-bacterial and anti-inflammatory properties of capric acid against Propionibacterium acnes: a comparative study with lauric acid. J Dermatol Sci. 2014;73(3):232-40.

6. Pretsch A, et al. Antimicrobial and anti-inflammatory activities of endophytic fungi Talaromyces wortmannii extracts against acne-inducing bacteria. PLOS One. 2014;9(6):e97929.

7. Chae H-S, et al. Euphorbia supina inhibits inflammatory mediators in mouse bone marrow-derived mast cells and macrophages. Int Immunopharmacol. 2015;29(2):966-73.

8. Song $Y$, et al. Determination of polyphenol components of Korean prostrate spurge (Euphorbia supina) by using liquid chromatography — tandem mass spectrometry: overall contribution to antioxidant activity. J Anal Methods Chem. 2014;2014

9. Joung D-K, et al. Antibacterial effect of Euphorbia supina extracts against methicillin-resistant Staphylococcus aureus under dark and light intensity. Afr J Pharm Pharmacol. 2011;5(18):2056-61.

10. Han M-H, et al. Polyphenols from Korean prostrate spurge Euphorbia supina induce apoptosis through the Fas-associated extrinsic pathway and activation of ERK in human leukemic U937 cells. Oncol Rep. 2016:36(1):99-107.

11. Mouser PE, et al. Propionibacterium acnes-reactive $T$ helper-1 cells in the skin of patients with acne vulgaris. J Investig Dermatol. 2003;121(5):1226-8.

12. Leyden JJ. Therapy for acne vulgaris. N Engl J Med. 1997;336(16):1156-62.
13. Lyte P, Sur R, Nigam A, Southall MD. Heat-killed Propionibacterium acnes is capable of inducing inflammatory responses in skin. Exp Dermatol. 2009; 18(12):1070-2.

14. Luyen BTT, et al. Anti-inflammatory components of Euphorbia humifusa Willd. Bioorg Med Chem Lett. 2014;24(8):1895-900.

15. Crespo I, San-Miguel B, Mauriz JL, Ortiz de Urbina JJ, Almar M, Tunon MJ, Gonzalez-Gallego J. Protective effect of protocatechuic acid on TNBSinduced colitis in mice is associated with modulation of the Sphk/S1P signaling pathway. Nutrients. 2017;16, 9(3)

16. Wang Y, Zhou J, Fu S, Wang C, Zhou B. Preventive effects of protocatechuic acid on LPS-induced inflammatory response in human gingival fibroblasts via activating PPAR- $\gamma$. Inflammation. 2015;38(3):1080-4.

17. Fei X, Je IG, Shin TY, Kim SH, Seo SY. Synthesis of gallic acid analogs as histamine and pro-inflammatory cytokine inhibitors for treatment of mact cell-mediated allergic inflammation. Molecules. 2017:29(22):6.

18. Ferk F, Kundi M, Brath H, Szekers T, Al-Serori H, Misik M, Saiko P, Marculescu R, Wagner KH, Knasmueller S. Gallic acid improves health-associated biochemical parameters and prevents oxidative damage of DNA in type 2 diabetes patients: Results of a placebo-controlled pilot study. Mol Nutr Food Res 2018, 62.4. https://doi.org/10.1002/mnfr.201700482.

19. Jin L, Piao ZH, Sun S Liu B, Kim GR, Seok YM, Lin MQ, Ryu Y, Choi SY, Kee HJ, Jeong MH. Gallic acid reduces blood pressure and attenuates oxidative stress and cardiac hypertrophy in spontaneously hypertensive rats. Sci Rep. 2017;7(1):15607.

20. Olafsdottir A, et al. A heteroglycan from the cyanobacterium Nostoc commune modulates LPS-induced inflammatory cytokine secretion by THP1 monocytes through phosphorylation of ERK1/2 and Akt. Phytomedicine. 2014;21(11):1451-7.

21. Lee WL, Shalita AR, Suntharalingam KS, Fikrig SM. Neutrophil chemotaxis by Propionibacterium acnes lipase and its inhibition. Infect Immun. 1982;53(1):71-6.

22. Lee $W$ - $R$, et al. Protective effect of melittin against inflammation and apoptosis on Propionibacterium acnes-induced human THP-1 monocytic cell. Eur J Pharmacol. 2014;740:218-26.

23. Kistowska $M$, et al. IL-1 $\beta$ drives inflammatory responses to Propionibacterium acnes in vitro and in vivo. J Investig Dermatol. 2014;134(3):677-85.

24. Grange PA, et al. Nicotinamide inhibits Propionibacterium acnes-induced IL-8 production in keratinocytes through the NF-KB and MAPK pathways. J Dermatol Sci. 2009:56(2):106-12.

25. Rottboell $L$, et al. Exploring Valrubicin's effect on Propionibacterium acnesinduced skin inflammation in vitro and in vivo. Derm Rep. 2015;7(3).

26. Lin Z-C, et al. Eupafolin nanoparticles protect $\mathrm{HaCaT}$ keratinocytes from particulate matter-induced inflammation and oxidative stress. Int J Nanomedicine. 2016;11:3907.

27. Lee $W$ - $R$, et al. The protective effects of Melittin on Propionibacterium acnes-induced inflammatory responses in vitro and in vivo. J Investig Dermatol. 2014;134(7):1922-30

28. Lee WJ, Lee KC, Kim MJ, Jang YH, Lee SJ, Kim DW. Efficacy of red or infrared light-emitting diodes in a mouse model of Propionibacterium acnes-induced inflammation. Ann Dermatol. 2016;28(2):186-91.

Ready to submit your research? Choose BMC and benefit from:

- fast, convenient online submission

- thorough peer review by experienced researchers in your field

- rapid publication on acceptance

- support for research data, including large and complex data types

- gold Open Access which fosters wider collaboration and increased citations

- maximum visibility for your research: over $100 \mathrm{M}$ website views per year

At $\mathrm{BMC}$, research is always in progress.

Learn more biomedcentral.com/submissions 